neighbourhood with droplets of infected saliva, and in the second place dishes and other utensils soiled by the patient should be sterilised regularly and all discharges burned. But we do not recommend "sniffing" salt water up the nose as an influential medical corporation has recently done.

Each epidemic wave of disease has certain charaeters that distinguish it from other epidemics of the same disease. Many observers must be able to recall influenza epidemics in which cases of serious osseous destruction in and about the middle ear were very prevalent. At the present time this grave complication seems to be less common, but we are meeting, on the other hand, with a large number of cases of pharyngeal inflammation, amounting often to cellulitis of the peritonsillar and retropharyngeal regions, sometimes simulating diphtheria, sometimes resembling the more severe scarlatinal throat. Ábscess-formation is not uncommon, and there is always great swelling around and enlargement of the cervical glands, with such constitutional phenomena as high fever and delirium. This type of the disease is tedious and depressing to the general health and resistance, but it tends to recovery in most of the cases in about ten days from the onset.

D. M.

\title{
THE CLASSIFICATION OF THE SYNDROMES OF ASSOCIATED LARYNGEAL PARALYSES.
}

\author{
By Dr. Maurice Vernet (Marseilles).
}

Fon their long passage from their terminal ramifications in the muscles of the larynx to their starting-point on the level of the bulbo-nucleus, the nervous motor-fibres of the vocal cords are liable to a great variety of injuries. This is what explains the constantly increasing number of forms which have been described of simple recurrent paralyses and of laryngeal associated paralyses.

The simple recurrent paralyses, that is to say manifesting themselves only by the paralysis of a vocal cord, are well known when they are caused by aortic aneurysm, by cancer of the cesophagus or by goitre, for example.

But as one follows upwards, towards the base of the cranium those recurrent fibres may be seen first going along in the pneumogastric cervical trunk, passing afterwards through the internal branch of the spinal nerve, and effecting, at that level, more and more intimate anatomic connection with the four last cervical nerves-the glossopharyngeal, the pneumogastric, the spinal accessory (external branch), and the hypoglossal nerves. These relations of proximity are continued alike in the cranial cavity and even to their starting-point in the bulb, where they are in immediate contact. So, by ascending the recurrent fibres it may be noticed that anatomically every cause of compression or physiological change of these fibres can influence simultaneously to a more or less extent the participation of one or several neighbouring nervous trunks. Simple laryngeal hemiplegia becomes an associated laryngeal hemiplegia. From the great variety of associated lesions a great variety of syndromes result.

There is no one who has not met with real difficulties in the study of such a question, whether in what concerns the classification of the syndromes or what refers to their representation. 


\section{December, 1918.] Rhinology, and Otology.}

This is due to several causes: On one hand, until now, the limited extent of our knowledge of the precise distribution of some of these cranial nerves or of the signification of disturbances recognised at the present time to be in dependence on them; on the other hand, a lack of method.

Our new observations were made notwithstanding the multiplicity of the forms already described; they did not always find room in the existing frameworks. The authors of these observations then proposed a new variety of syndromes. Messrs. Rose and Lemaitre (1) wrote in 1907: "One could create as many syndromes as there may be of paralytic combinations."

The real difficulty is, perhaps, not in the variety of combinations or syndromes, but, we believe, more in their signitication or their representation.

Let us retrace the chief stages which enable us to view the question. as a whole. We may recall the following forms :

In 1864 Hughlings Jackson (2) was the first to call attention to the homolateral paralytic association of the larynx, of the soft palate, of the tongue, and of the muscles of the neck (sterno-cleido-mastoid and trapezius).

In 1891 Avellis (3) describes the palato-laryngeal hemiplegia.

In 1892 Schmidt (4) the paralysis of the soft palate, of the larynx, and of the neck muscles (sterno-mastoid and trapezius).

In 1906 Tapia (5) brings, in his turn, the description of the syndrome characterised by the paralysis of the tongue on one side and of the larynx on the same side.

In 1915 Collet (6) describes the total hemiplegia syndrome of the last four cranial nerves (7) to (13).

In 1915 (14) I isolated, for the first time, the hemiplegia of the soft palate, larynx and pharynx-the characteristic syndrome of the three nerves of the foramen lacerum posterius (15) to (19).

By the side of those syndromes, of which we shall see the importance in the classification which will follow, we find a certain number of observations collected by Broeckaert (20) in 1907 of the paralyses of the recurrent nerve associated with the paralysis of the great sympathetic nerve on the same side.

In 1910 Garel and Gignoux (21) call attention to the paralyses of the recurrent nerve associated with paralysis of the sterno-mastoid and the trapezius, without any paralysis of the soft palate.

Other observations show the association of the recurrent paralysis with paralysis of the branchial plexus on the same side (Collet and ourselves).

Finally, some authors-Poli (22) in particular-quote a certain number of cases gathered under the name of "atypic" forms and of "crucial" forms.

It is obvious that such a variety of paralytic combinations may appear as inordinately extended ground. Of all the attempts at classification made until now, none of them seem to have brought the necessary foundations for a strict systematisation.

Rose and Lemaitre (loc. cit.) propose to substitute instead of the terminology by proper names, evidently without a precise signification, a designation of the syndromes by the organs injured. From this point 
of view the matter gains evidently in clearness. Jackson's syndrome becomes glosso-palato-laryngeal hemiplegia or glosso-palato-scapulolaryngeal, according to the incompleteness or completeness of the syndrome-that is to say, without or with paralysis of the muscles of the neck. One could name similarly Schmidt's syndrome, the scapulopalato-laryngeal hemiplegia.

This designation by each organ could be represented in its essential forms by the following schema:

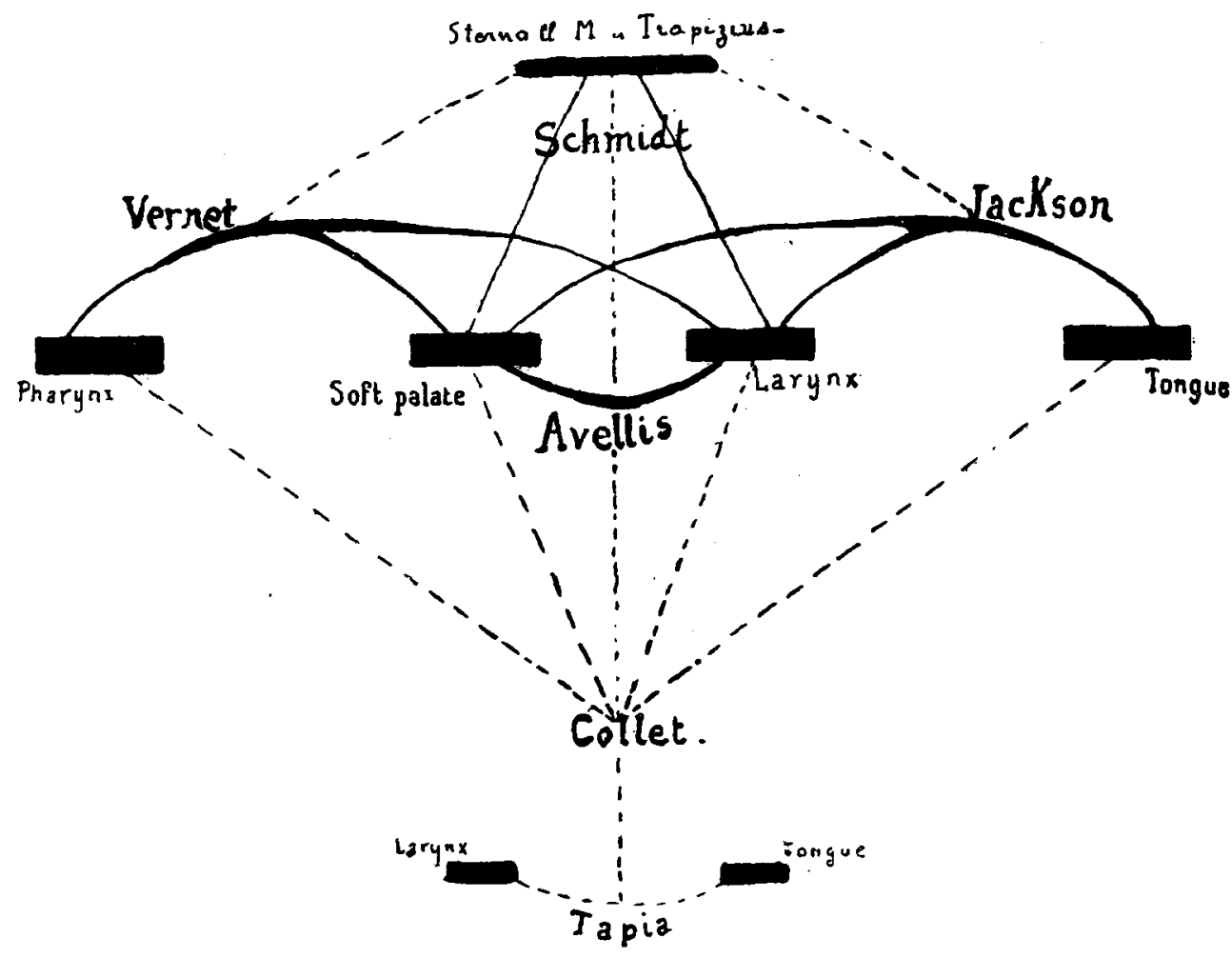

Fig. I

Schema representing by organs the paralytic syndromes observed, depending upon the last four cranial nerves.

But several objections can be raised to this designation. On one hand, certain forms (as the glosso-scapulo-palato-laryngeal hemiplegia) are long appellations, and upon the whole not easily understood as regards the representation of the lesions. On the other hand, this designation, that would be satisfactory if each of the injured organs were to have a single innervation, becomes defective and insufficient for organs whose innervation is, at least, double or triple, as, for instance, the tongue, the pharynx, and the soft palate.

Just as in the case of the limbs, we are obliged to take into consideration the phenomena of sensitive (sensory) paralysis as well as 
those of motor paralysis, and, I may add, those of special sense paralysis as well as those of sensory paralysis.

This is the case in the tongue, of which the motor innervation arises from the hypoglossal, the sensory innervation from the trigeminal, and the pneumogastric, and the sensorial (special sense) innervation from the glosso-pharyngeal nerves. It is important to determine what is due to each of them to allow an estimation of the gravity, and, at times, of the nature of the causal lesion.

In limiting ourselves only to the motor phenomena, the appellation by organs does not limit by any means the varieties of paralytic combinations, as is shown in the following attempt at classification by Sanz (23), who has been able to isolate at least ten possible forms ; and we must notice that the pharynx is not included in these varieties.

The author represents each organ by an initial :

Soft-palate, p.; vocal cord, v.; sterno-mastoid and trapezius, m.; tongue, $t$.

Here are these various combinations:

P.v.m., p.m., v.m., p.v.t., p.t., v.t., m.t., p.v.m.t., p.m.t, v.m.t.

In 1906 Poli (loc. cit.), in a highly documented brochure, proposed a different classification, and distinguished the forms of syndromes into " simple forms," "associated forms," and "symptomatic forms."

This classification divides still more the variety of the syndromes instead of creating determined and exact forms. Besides the difficulty of fixing with certitude that such a case results from such a form (a simple form or a symptomatic form, for instance), it is to be observed that the associated forms are very often symptomatic or vice versâ. We have previously alluded to the importance of the sensitivo-sensorial disorders in the study of these syndromes.

If we consider that till now, and in the author's mind, the distinction of the peripheral and central forms were made upon the modifications or upon the integrity of the sensibility (or, again, upon the reaction of degeneration), we cannot but reject such a point of view, seeing that the central as well as the peripheral forms may present the same disorders of sensibility.

M. Sicard, devoting an interesting dissertation to this question, rightly considers that " the only olassification which has any practical importance is that which would, at first, obey the topographic lesional diagnosis and afterwards the ætiologic diagnosis."

This is, in reality, the aim that each classification must essentially seek to attain. But a topographic and ætiologic diagnosis is only possible or easy as far as the syndromes appear themselves simple in their anatomic and clinical representation, and limited in determined and precise types. We must therefore seek a classification-clear, that is to say, pointing out the paralytic associations in such a way that all the lesions that a given syndrome admits may be evoked, all at once, in the mind-avoiding the use of proper names without any exact signification, creating limited types, but sufficient to contain easy combination of association. Only an anatomo-physiologic classification can fulfil these conditions. Therefore we have proposed to designate precisely each paralysis or paralytic syndrome by each or all of the nervous trunks concerned in each of them, as we do with regard to other nervous trunks or plexuses of the organism. This is a question not only of simplification, but of method.

If it is difficult, for instance, to a mind unfamiliar with such 
paralytic combinations to evoke rapidly under the name of Schmidt's syndrome what this appellation represents, it is obviously easier to do so with the simple designation of spinal paralysis. It is the same thing evidently concerning more complex combinations between each of the four nervous cranial trunks proceeding from the basis of the

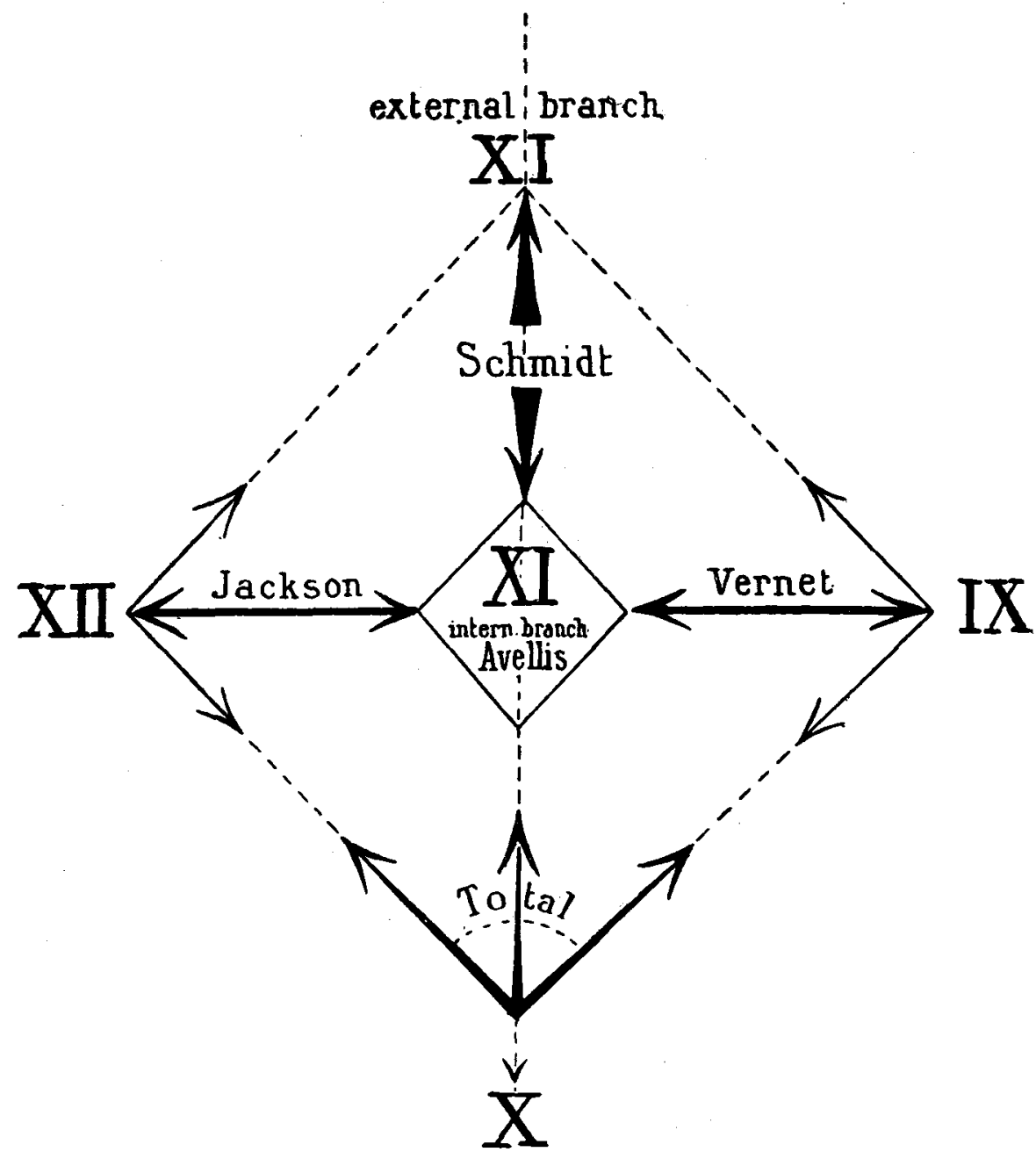

FIG. II

cranium-the ninth (glosso-pharyngeal), the tenth (pneumogastric), the eleventh (spinal), and the twelfth (hypoglossal) nerves. Who does not picture to himself clearly under the name of "spinal and hypoglossal paralysis " the syndrome illustrated till now by the name of Jackson?

Such a designation of the syndromes of laryngeal associated paralyses, based on the lesion of the nervous trunks properly called, 
besides its advantage of obvious clearness, offers that of a more exact and more complete representation of all the symptoms-more exactly in so far that it informs us, at once, on the probable seat and the extent of the lesions concerned (in the sense indicated by M. Sicard), more completely because it does not exclude from the clinical list certain sensitivo-sensorial troubles, pulmonic or cardiac, for instance, which the simple designation of the chief organs injured would omit. This designation finally creates exact types, pointing out with great clearness the number of possible combinations, limiting them to the essential forms.

If, in fact, the paralyses of the terminal branches of these nervous trunks may be multiple and varied, they constitute only modalities, more or less rough, sketched from the preceding ones; their clinical appearance is very peculiar; their interpretation, not causing, as a rule, any difficulty, is of less interest.

The truncal paralyses alone constitute syndromes having a real clinical individuality and a diagnostic interest of first rank.

We have tried to represent in a schema the various combinations of associated laryngeal paralyses, taking into consideration each of the four nervous trunks in its paralytic association with the internal branch of the eleventh, which is the nerve of the larynx, and in retaining only the forms where one at least of these nervous trunks is concerned.

At each of the corners of the square represented, one of the four cervical nerves-ninth, tenth, eleventh, twelfth-is found. Some of the associations thus constituted are, as we can see, completely limited from this point of view.

We have purposely indicated, for comparison, beside each association, the name that has been given until now to the corresponding syndrome. The arrangement of the arrows in heavy type shows their essential composition.

In adopting this nomenclature by nervous trunks we could indicate the syndromes of associated laryngeal paralyses in the following manner :

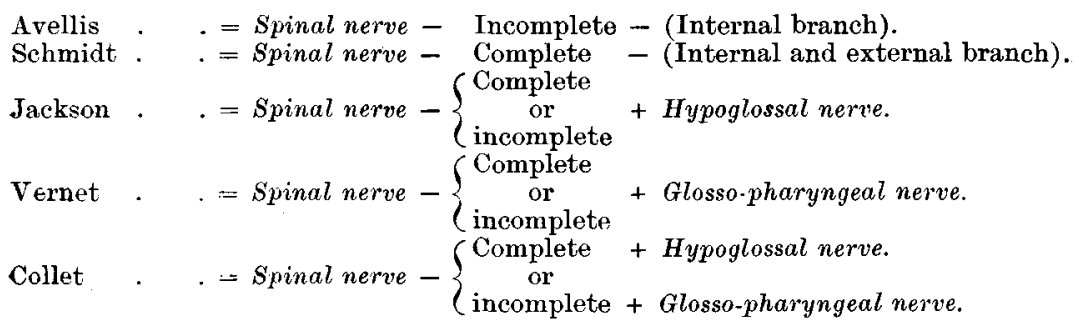

Each of them with or without the pneumogastric nerve.

It should be noticed that we are representing the pneumogastric nerve as an accessory in this nomenclature. We consider the tenth properly called as being or not being susceptible of inclusion in each of these forms. We have tried to show, by basing our argument upon clinical notions and upon the present general opinion of physiologists, that this nerve must be considered as solely sensitive,' consequently as

1 Vernet, “Associated Iaaryngeal Paralysis," 1916, pp. 56 and 75, and Rev. Neurol., 1918. 


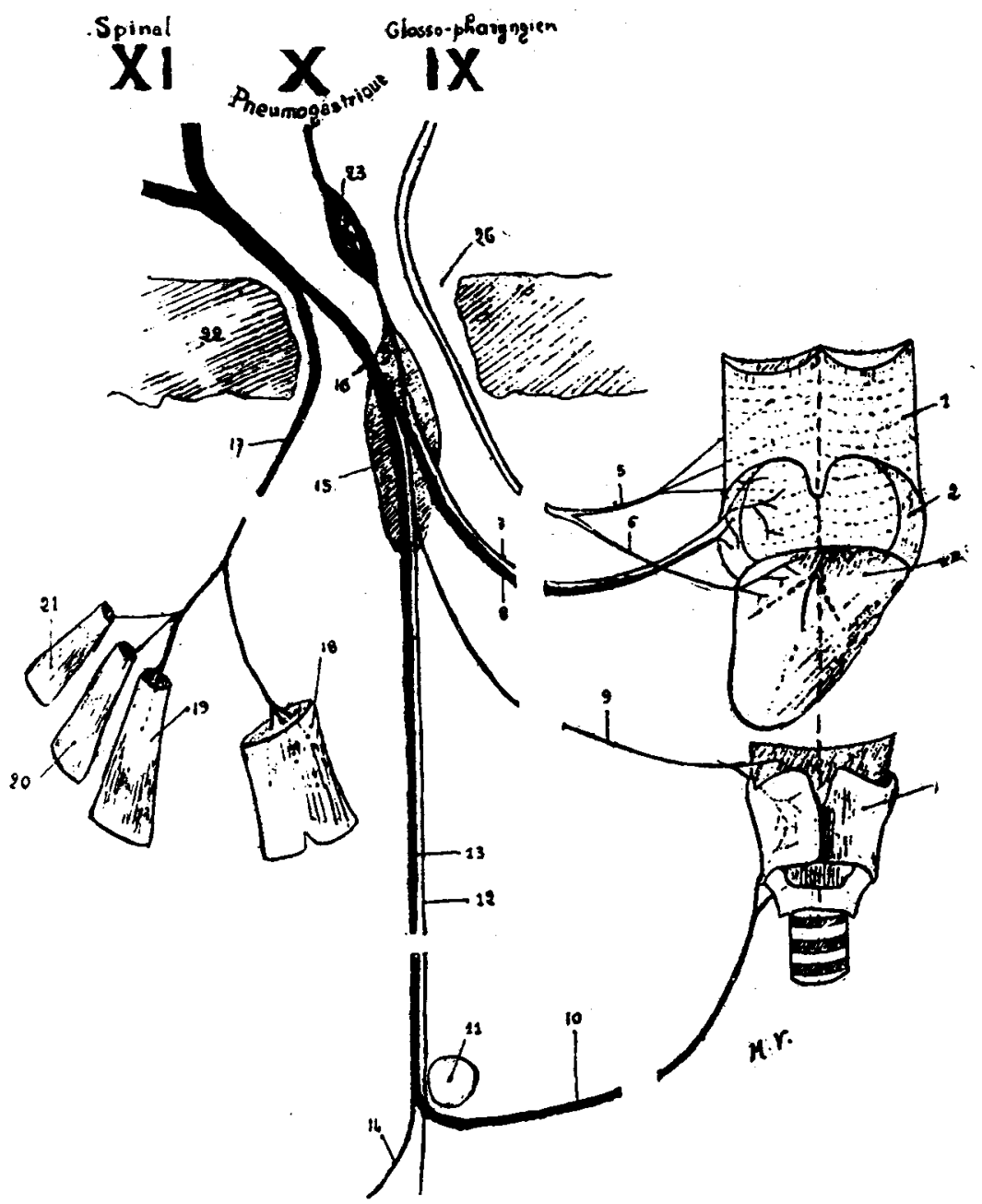

FIG. 3.- Schematic distribution of the three cranial nerves issued from the foramen lacerum posterius. By the author. 1. Superior constrictor musele of the pharynx. 2. Soft palate. 3. Tongue, 4. Larynx. 5. Motor fibres of the IXth for the superior constrictor of the pharynx. 6. Gustatory fibres from the IXth for the posterior third of the tongue. 7. Sensitive fibres issued from the Xth for the soft palate and the mucous membrane of the buccal part of the pharynx. 8. Motor fibres issued from the XIth for the soft palate. 9. Superior laryngeal nerve (sensitive fibres issued from the $X$ th, sometimes a few motor fibres issued from the XIth for the m. crico-thyroid. 10. Recurrent (motor fibres issued from the internal branch of the XIth). 11. Subclavius muscle. 12. Pneumogastric. 13. Motor fibres (laryngeal and cardio-moderator) issued from the XIth going along the neck in the trunk of the Xth. 14. Cardio-moderator fibres. 15. Plexiform ganglion. 16. Internal branch of the XIth. 17. External branch of the XIth. 18. Sternocleido-mastoid. 19. Clavicular fasciculus of the trapezius. 20. Obcromial fasciculus of the trapezius. 21. Spinal fasciculus of the trapezius. 22. Basis of the cranium. 23. Jugular ganglion. 24. Foramen lacerum posterius. 
intervening in the modalities of associated laryngeal paralyses only to complete the clinical list without modifying anything of their essential paralytic form.

All the same a very considerable interest exists in noticing carefully the degree and value of its physiological change when it exists by the side of that of other nerves. So much the more, the disorders in its dependence may singularly enlighten a diagnosis of the seat and of the extent of the lesions, whose importance we have already mentioned. It

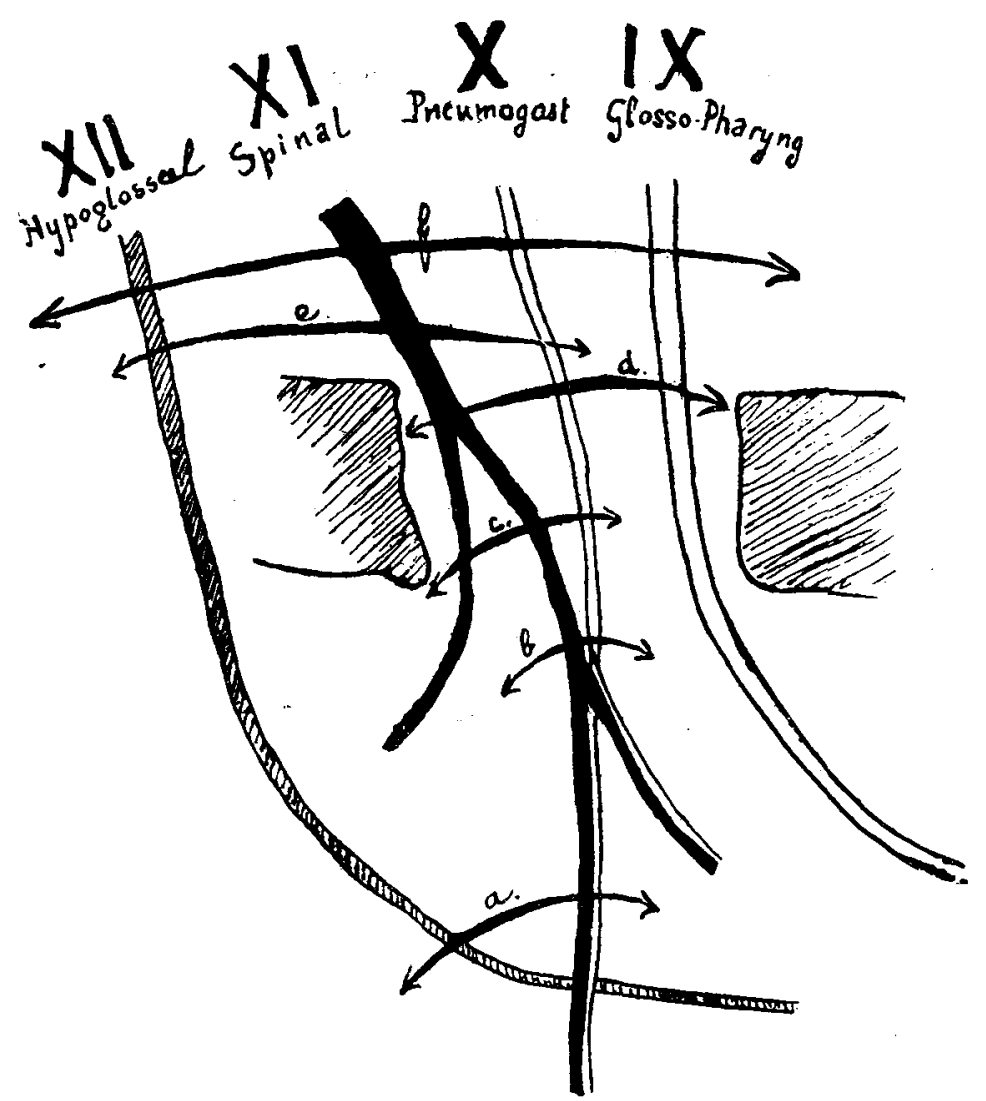

FIo. 4.-Schema representing by nerves the syndromes of associated laryngeal paralysis. a. Tapia. b. Avellis. c. Schmidt. $d$. Vernet. e. Jackson. $f$. Collet-Sicard.

is for that reason that we have represented in our schema the tenth as being of the same importance as the eleventh, the twelfth and the ninth.

Each of the schematised associations has been united to it by a dotted line and a common arrow. It is the same thing for the external branch of the spinal nerve, which, by its anatomical disposition, may or may not be concerned.

This schema may be made more explicit by representing the distribution of the nerves themselves, which it is necessary to have 
present in the mind. In the two designs (Figs. 3 and 4) we find on one hand the schematic distribution of the nerves, on the other, the associated lesions traced out on the nerves themselves.

Finally, we recapitulate, in a general list, the principal symptoms depending on each nerve :

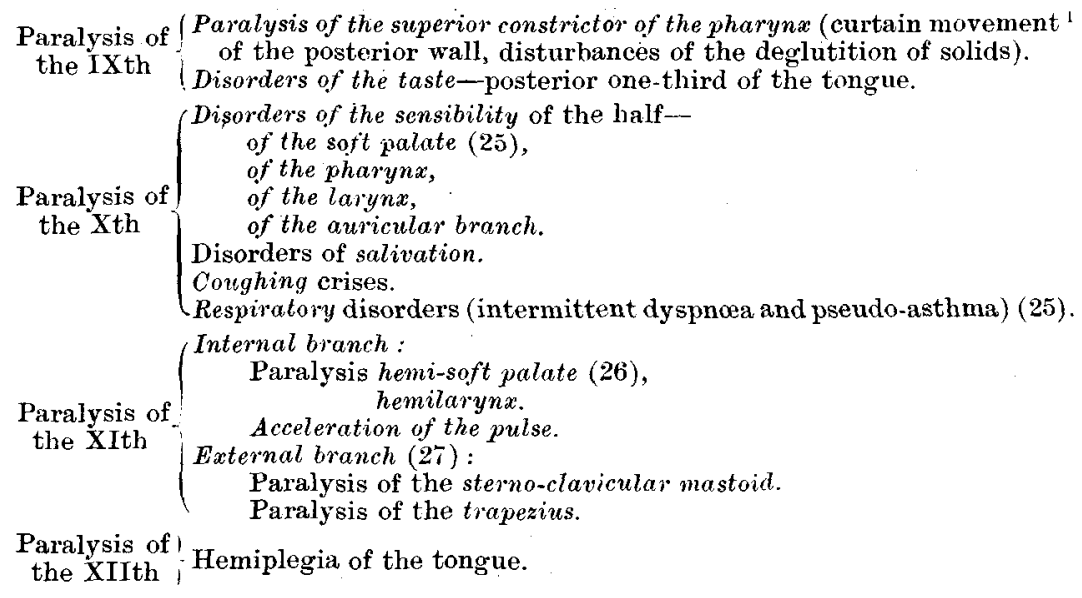

The question thus limited, all the interest then resides obviously in the diagnosis of lesional topography and the atiologic diagnosis. It clearly appears that our classification facilitates in a great measure such precisions. The designation by nerves keeps in fact all its value whatever may be the seat (radicular peripheric, bulbar, or bulbo-medullar) of the lesion.

All the above syndromes ${ }^{2}$ may be realised by a bulbar lesion, as they are at the periphery. But we must acknowledge that in general they are then, themselves, associated with another disease, of the axis cerebro-spinal, hemiplegia, hemianæsthesia, tabes, sclerosis in patches, syringomyelia, etc., in the frame of which they are merely an epiphenomenon-a symptom.

From this point of view each simple syndrome, formed at the expense of the last cranial nerves, ought to be considered as peripheric, every other syndrome as central.

We wrote ${ }^{3}$ as early as 1916

"The bulbar forms of associated laryngeal paralysis rarely exist in a simple state. . . . One must doubt, in general, of the bulbar

1 By curtain movement is meant a movement of removal of the pharyngeal wall of the mucosa, similar to the movement made by a curtain which one draws. This movement is the characteristic sign of the paralysis of the glosso-pharyngeal nerve.

2 We have been able to observe a total syndrome of the four last cranial nerves of a bulbar origin exactly similar to an analogous syndrome of peripheric origin from the point of view motor and sensitivo-sensorial. But a clear and persistent hemiparesis of the limbs and the mode of beginning allowed us to determine clearly the lesional topographic seat. We have at the present time a series of other cases (about fifteen, published or still unpublished) upon the syndromes of the last four nerves of exo- or endo-cranial origin, or upon the simple syndromes of the foramen lacerum posterius, or Jackson's syndromes.

3 Loc. cit., pp. 107 and 108. 
origin of an associated syndrome which evolves singly for a long length of time, and think rather of a peripheric cause in the forms of a slow commencement."

M. Sicard concludes still more formally to decide a diagnosis of exo- or endo-cranial localisation: "The simple form of the syndrome always denotes an exo-cranial origin."

That is incontestable for the simple forms of associated and complex laryngeal paralyses, that of the four last cranial nerves or that of the three nerves of the foramen lacerum posterius, for instance. We can admit, as a rule, that it is the same thing for the simple paralysis of the pneumogastric, of the total spinal and hypoglossal nerves (formerly Jackson).

Harmer wrote, in 1902: "I have not found any case in medical literature of the unilateral paralysis of the tongue, of the soft palate, of the larynx, and of the muscles of the neck in which a bulbar seat of the affection may be demonstrated."

We think that it is exactly the same for a certain number of observations published till now under the name of Avellis's syndromes or Schmidt's syndromes where it has been found impossible to produce a diagnosis of localisation.

In a great number of these observations some perturbations of deglutition, evident enough, were related, without paralysis of the glis:o-pharmand. which was till then misunderstood, being suggested in atuse. T'he dianmusic of this paralysis would have made it possible to ascertain the paralytic association of the three nerves of the foramen lacerum posterius and to localise definitely the causal lesion at that spot, as we have already shown. The paralysis of the glosso-pharyngeal, of the pneumogastric, and of the spinal nerves is, in fact, always peripheric in the simple state.

We can see in the first work that I wrote on this subject ("The Syndrome of the Foramen Lacerum Posterius," Vernet, "The Associate Laryngeal Paralyses," pp. 152 to 170 ) some very remarkable observations on this point of view, and in particular an observation of Rose and Lemaitre, where a diagnosis of bulbar localisation was stated as a simple svudrome of the foramen lacerum posterius, an observation by Tilley (28), one by Desvernines (29), etc. The observation that I published in the Paris medical, January 27, 1917, is of the same order.

Does that allow us to infer an absolute rule, that is to say, that each simple syndrome is peripheric? One cannot be so affirmative. There exist, incontestably, apart from the preceding cases, examples where the diagnosis of topographical lesion, and, with still greater reason, the atiologic diagnosis, cannot be precisely indicated, notwithstanding a thorough examination. Out of more than fifty cases which I have been able to gather of sundromes described till now under the name of Avellis's syndromes (paralysis of the internal branch of the eleventh), three times out of five only an atiologic diagnosis could be stated, besides frequently vague.

Certainly some of these cases are wanting in clinical information, but, for the most part, the general clinical examination was circumstantial enough.

What elements would permit in these cases a lesional localisation?

We have said that the perturbances of the sensibility in the pneumogastric and glosso-pharyngeal region, contrarily to what was formerly asserted, could be cited as well in the paralyses of bulbar origin as in 
those of radicular ${ }^{1}$ or peripheric origin. The reaction of degeneration cannot be taken as characteristic of a paralysis of peripheric origin.

M. Sicard has shown that the examination of the cephalorachidian liquid could not by itself give useful information as to the exo- or endo-cranial localisation. "The clinical signs," he says, " appear more important with regard to the diagnosis than the rachidian humoral reactions."

It is, in fact, much more from the manner of beginning, the manner of the evolution of the symptoms, from the examination of the sensibility or of the peripheric motricity, from the verifying of ocular or pupillary signs, or in the examination of reflex movements, etc. . . . that one could usefully settle the clinical examination of apparently simple syndromes of which a diagnosis of lesional topography would be uncertain.

The resolution of the clinical problem is only possible inasmuch as a given syndrome is clearly defined by exact anatomical and physiological representation.

\section{Bibliography.}

(1) Rose and Lemaître.- “The Palato-laryngeal Hemiplegia," Ann. des Mal de l'Oreille et du Larynx, 1907, No. 11.

(2) Hughuings Jackson.-1864. See Mackenzie, Brit. Med. Journ., March 2, 1883.

(3) Aveluis.-Beriner Klinik, 1891, xl, and Arch. f. Laryng. und Rhinol., 1900, book $\mathrm{x}$.

(4) SснміDт.- “ Die Krankheiten der Oberen Luftwege,” Berlin, 1897, p. 48.

(5) Tapia.-Communication at the Congress of Lisbon, 1906, Arch. Internat. de Laryngol, 1906 , p. 780.

(6) Collet.-Lyon Méd., April, 1915̃, No. 4.

(7) VERnet._- "On the Total Syndrome of the four last Cranial Nerves," Bull. de la Soc. Méd. des. Hôp. de Paris, February 24, 1916.

(8) Lannois, Sargnon, and Vernet.- "Two Cases of Total Syndrome by War Wounds," Rev. Neurol., June, 1916, pp. 943 and 948.

(9) Sicard.-Marseille Méd., March 1, 1917, No. 13.

(10) Villa Ret.-Paris Méd., May 26, 1917.

(11) Sicard, Rogrr and Vernet.-" "Paroxysmic Pharyngeal Algia Syndrome, Post-operatory, of Paralysis of the four last Cranial Nerves," Marseille Méd., Military Medico-Surgical Society of the XVth Region, record of December 8, 1917.

(12) Livon-BerLin and Vernet.- " Concerning a Case of Paralytic Syndrome of the four last Cranial Nerves; Extraction of Shell Fragment situated at the Basis of the Cranium," Marseille Méd., June 15, 1917.

(13) Lannois and Joutr.-_" A Case of Total Syndrome," Lyon Méd., p. 424.

(14) Vernet.- "The Associated Laryngeal Paralyses," Lyon, 1916 ; "The Syndrome of the Foramen Lacerum Posterius," Paris Méd., January 27, No. 4.

(15) Alorn.--CConcerning the Foramen Lacerum Posterius Syndrome," Paris Méd., January 12, 1918.

(16) Hatphen.- "A Case of Foramen Lacerum Posterius Syndrome," Medical meeting of the 4th Army, June 7, 1917.

(17) Lannois and Bourcard.-Lyon. Méd., January, 1917, No. 1.

(18) Bellin and Vernet. Marseille Méd., December 1, 1916.

(19) Guyot and Angles d'Auriac.-Paris Méd., September 8, 1917.

(20) Bromckaert. - Presse Oto-Rhino-Laryngol. Belge, 1907.

(21) Gianoux.-Ann. des Mal. de l'Oreille et du Larynx, 1910, p. 505.

1 Messrs. Sicard and Rimbaud have related to the Medico-chirurgical Society of the XVth Region, in the meeting of May 24, 1917, a new and interesting case from this point of view (a case of condyloid lacerum posterius foramina syndrome of an endo-eranial origin). Moreover, one may find with regard to the same case a diagnosis of topographical lesion which confirms the preceding views. See this number of Marseille Médical, p. 587, and Paris Médical, September 8, 1917. 
(22) Polt.-Communication at the Ninth Congress of the Laryngological, Otological, and Rhinological Italian Society, Roma, Oetober, 1905.

(23) Sanz.-A $\gamma^{\prime}$. Intern. d'Otol. et de Laryngol., 1911, pp. 469, 679. 1916.

(24) Vernet.- "The Glosso-pharyngeal Paralysis," Paris Méd., December 23,

(25) Idem.-_"The Pneumogastric Paralysis,” Paris Méd., March 10, 1917; "Respiratory Disorders in the Paralysis of the Pneumogastric Nerve," Soc. Med. des Hốp. de Paris, record of December 21, 1917.

(26) Lermotez.-Ann. des Mal. de l'Oreille et au Larynx, 1898, p. 564.

(27) SICard.- "The External Spinal Paralysis," Rev. Neurol., 1909, and Marseille Med., May 15, 1917.

(28) TilLEY.-Society of Laryngology of London, meeting of December 2, 1898.

(29) Desvernines. - Ann. des Mal. de l'Oreille et du Larynx, Paris, 1901, p. 534.

\section{A NOTE ON SCHULTZE'S MONOCHORD.}

By W. M. Mollison.

The determination of the upper limit of the range of hearing gives interesting, if not valuable, results.

Recently the Otological Section of the Royal Society of Medicine approved a "standard" scheme for the testing of the hearing; in that scheme the determination of the range of hearing was included, and it was suggested that Galton's whistle or the monochord should be used to investigate the upper limit of the range.

It is the endeavour of these notes to establish the claims of the monochord over the Edelmann-Galton whistle, as an instrument of greater precision, and therefore more worthy to be used where a standard is aimed at.

The monochord consists essentially of a steel wire stretched between projections at either end of a steel bar; on the bar is a "bridge" which grips the wire and thus can vary the effective length of wire; for convenience the bar is provided with a handle.

In practice the wire is $50 \mathrm{~cm}$. long, and the bar is marked off in centimetres; this length of wire does not give low enough notes for all cases; to meet this a longer frame can be made.

The wire is a steel wire (a "banjo" wire), gauge 26 .

The notes are produced by rubbing the wire in its length with a piece of wool soaked in methylated spirit or turpentine; the wool is held between the finger and thumb, and the wire pinched while the wool is pulled along the wire.

An alternative method is to use a piece of chamois leather coated with powdered resin, but this is not quite so easy to use.

With a little practice the most effective method of rubbing will be discovered: for the highest notes a short, hard rub is best, for lower notes a lighter rub, and one on that part of the wire nearer the bridge gives a clearer and cleaner note. It is easier to produce clear notes with a heavy frame.

In the production of high notes there is always the difficulty of overtones, and even when the note sounds simple to the normal ear there well may be overtones that are imperceptible.

The advantages of this instrument seem to be:

(1) It is easily standardised ; the gauge of the wire can be fixed, and a steel piano-wire, of known composition, chosen; granted this all 